\title{
Very Short Answer Questions: The Answer to the Perfect Medical Assessment? [Letter]
}

This article was published in the following Dove Press journal:

Advances in Medical Education and Practice

\author{
Imran Karim Janmohamed (iD) \\ Mohammed Haris \\ Javed-Akhtar (iD ${ }^{2}$ \\ Hamza El-Omar (iD ${ }^{2}$ \\ 'University of Leeds, Faculty of Medicine \\ and Health, Leeds, UK; ${ }^{2}$ Imperial College \\ London, School of Medicine, London, UK
}

Correspondence: Imran Karim Janmohamed

University of Leeds, Faculty of Medicine and Health, Worsley Building, Clarendon

Way, Leeds LS2 9JT, UK

Tel +44 7704905 I I2

Email umI5ikj@leeds.ac.uk

\section{Dear editor}

We read with great interest the study by Sam et al regarding a novel method of assessment in pathology, Very Short Answer Questions (VSAQs). ${ }^{1}$ The reliability shown by this method to discriminate between students and potentially improve learning behaviours were fascinating. We appreciate the authors' efforts in conducting this study; however, certain aspects need addressing.

Given that the technological aspects of this assessment produced some of the main benefits (such as faster marking), we wonder how widespread it would be adopted. As current and previous medical students at Imperial College London, we are aware that the medical school establishes an ongoing relationship between students and technology, as free iPads are issued to all students. ${ }^{2}$ However, such an integrated familiarity with technology does not exist at other medical schools, such as the University of Leeds. This must be considered in light of the positive feedback attained from students in the authors' previous study where they determined the validity of VSAQs ${ }^{3}$ thus, attempting to generalise the utility of VSAQs may be prone to bias.

Along this vein, the lack of external validation measures to evaluate exam performance calls for a need for research to examine the utility of VSAQs in a multicentre study. However, instituting such a novel assessment at other universities may experience more friction during the implementation stage. A 2011 paper from the University of Leeds, which extensively studies the effectiveness of technology-enhanced learning, discussed the financial costs associated with developing such ventures, stating: "the costs can only be recovered by providers if there is the economy of scale [...] or when they are extensively subsidised through grants or advertising." " Such a change would also call for increased work at the curriculum level, for example, to write tailored VSAQs and issue practice questions for students, and at the systems level, to establish an understanding of the software.

Additionally, it is worthwhile noting that UK junior doctor job allocations are considerably dependent on a student's academic ranking. Therefore, among medical students who wish to distinguish themselves, VSAQs might encourage recall of the academic minutiae characteristic of pathology. Studies have shown that medical school is already a stressful environment as students are expected to retain a large amount of information within a limited time frame. ${ }^{5}$ Thus, we fear that VSAQs may raise the risk of burnout as the volume of work in the penultimate year, during which they were proposed, is particularly large. If an institution was determined to 
use an assessment that tests recall, we would encourage the authors to explore employing VSAQs specifically in physiology and clinical scenarios of acutely unwell patients, critical areas to master as junior doctors.

The findings of this study are critical and the implementation of VSAQs may pay dividends in our future clinical practice. Nevertheless, we question the utility of such a novel approach regarding its impact on stress and wonder how it could accurately be assessed in a multicentre study given the barriers to uptake that may probably exist at other institutions.

\section{Disclosure}

The authors declare no conflicts of interest in this communication.

\section{References}

1. Sam AH, Peleva E, Fung CY, Cohen N, Benbow EW, Meeran K. Very short answer questions: a novel approach to summative assessments in pathology. Adv Med Educ Pract. 2019;10:943-948. doi:10.2147/ AMEP.S197977

2. Patel S, Burke-Gaffney A. The value of mobile tablet computers (iPads) in the undergraduate medical curriculum. Adv Med Educ Pract. 2018;9:567-570. doi:10.2147/AMEP.S163623

3. Sam AH, Field SM, Collares CF, et al. Very-short-answer questions: reliability, discrimination and acceptability. Med Educ. 2018;52 (4):447-455. doi:10.1111/medu.13504

4. Sandars J. The challenge of cost-effective technology-enhanced learning for medical education. Educ Prim Care. 2011;22(2):66-69. doi:10.1080/14739879.2011.11493970

5. Altannir Y, Alnajjar W, Ahmad SO, et al. Assessment of burnout in medical undergraduate students in Riyadh, Saudi Arabia. BMC Med Educ. 2019;19. doi:10.1186/S12909-019-1468-3

Dove Medical Press encourages responsible, free and frank academic debate. The content of the Advances in Medical Education and Practice 'letters to the editor' section does not necessarily represent the views of Dove Medical Press, its officers, agents, employees, related entities or the Advances in Medical Education and Practice editors. While all reasonable steps have been taken to confirm the content of each letter, Dove Medical Press accepts no liability in respect of the content of any letter, nor is it responsible for the content and accuracy of any letter to the editor.

\section{Publish your work in this journal}

Advances in Medical Education and Practice is an international, peerreviewed, open access journal that aims to present and publish research on Medical Education covering medical, dental, nursing and allied health care professional education. The journal covers undergraduate education, postgraduate training and continuing medical education including emerging trends and innovative models linking education, research, and health care services. The manuscript management system is completely online and includes a very quick and fair peer-review system. Visit http://www.dovepress.com/testimonials.php to read real quotes from published authors. 